\title{
Produção de biomassa por cultivos de cobertura do solo e produtividade do algodoeiro em plantio direto
}

\author{
Alexandre Cunha de Barcellos Ferreira(1), Fernando Mendes Lamas( ${ }^{(2)}$, Maria da Conceição Santana Carvalho ${ }^{(3)}$, \\ Júlio César Salton ${ }^{(2)}$ e Nelson Dias Suassuna(1)

\begin{abstract}
(1)Embrapa Algodão, Núcleo de Pesquisa do Cerrado, Caixa Postal 714, CEP 74001-970 Goiânia, GO. E-mail: acunha@cnpa.embrapa.br, suassuna@cnpa.embrapa.br (2)Embrapa Agropecuária Oeste, Caixa Postal 661, CEP 79804-970 Dourados, MS. E-mail: lamas@cpao.embrapa.br, salton@cpao.embrapa.br ${ }^{(3)}$ Embrapa Arroz e Feijão, GO-462, Km 12, Caixa Postal 179, CEP 75375-000 Santo Antônio de Goiás, GO. E-mail: conceicao@cnpaf.embrapa.br
\end{abstract}

Resumo - O objetivo deste trabalho foi avaliar a produção, a persistência da matéria seca e a eficiência da dessecação em espécies vegetais utilizadas para cultivos de cobertura do solo, e quantificar seus efeitos sobre a produtividade do algodoeiro em plantio direto. O trabalho foi realizado em Santa Helena de Goiás, GO, com 16 tratamentos: Panicum maximum, cultivares Mombaça, Tanzânia e Massai; Urochloa brizantha, cultivares Piatã, Xaraés, Marandu e MG4; U. decumbens; Paspalum atratum cv. Pojuca; Sorghum bicolor cultivares Santa Eliza e BRS 700; Pennisetum glaucum cv. ADR 500; Raphanus sativus; Eleusine coracana, Crotalaria spectabilis, além da testemunha em pousio. As espécies foram semeadas no início de março (2007). As espécies com menores produtividades e persistência da matéria seca foram C. spectabilis, E. coracana e $R$. sativus. As produtividades de algodão em caroço e fibra foram maiores no cultivo sobre palhas residuais das cultivares Tanzânia e Mombaça de $P$. maximum, em comparação às observadas com uso de $P$. atratum cv. Pojuca, R. sativus e pousio. Em geral, S. bicolor, P. glaucum e as cultivares Tanzânia e Mombaça de P. maximum, e MG4, Piatã e Xaraés de $U$. brizantha apresentam produção e persistência da matéria seca adequadas para o cultivo do algodoeiro no sistema de plantio direto, no cerrado brasileiro.

Termos para indexação: Brachiaria, Gossypium hirsutum, Panicum maximum, Urochloa, culturas de cobertura, palha.

\section{Cover crops biomass production and cotton yield in no-tillage system}

Abstract - The objectives of this work were to evaluate biomass production and persistence and the desiccation efficiency in plant species used as cover crops, and to quantify its effects on cotton yield in a no-tillage system. The study was carried out in Santa Helena de Goiás, GO, Brazil, using 16 plant species: Panicum maximum, cultivars Mombaça, Tanzânia and Massai; Urochloa brizantha, cultivars Piatã, Xaraés, Marandu and MG4; U. decumbens; Paspalum atratum cv. Pojuca; Sorghum bicolor cultivars Santa Eliza and BRS 700; Pennisetum glaucum cv. ADR 500; Raphanus sativus; Eleusine coracana, Crotalaria spectabilis, and fallow plants as control. The species were sown early in March-2007. The lower dry biomass productivity and persistence were obtained with $C$. spectabilis, E. coracana, and R. sativus. Cotton seed and lint yield were higher when it was cultivated after the cultivars Tanzânia and Mombaça of P. maximum, in comparison to the ones observed using P. atratum cv. Pojuca, R. sativus, and fallow plants. Generally, S. bicolor, P. glaucum and the cultivars Tanzânia and Mombaça of P. maximum, and MG4, Piatã and Xaraés of $U$. brizantha have biomass persistence and productivity suitable for cotton cultivation in no-tillage systems in the Brazilian savannah.

Index terms: Brachiaria, Gossypium hirsutum, Panicum maximum, Urochloa, cover crops, straw.

\section{Introdução}

Mais de $90 \%$ da área e da produção nacional de algodão estão situadas em áreas de cerrado (Companhia Nacional de Abastecimento, 2009). Em regiões de clima tropical, o sistema de plantio direto é importante para a conservação e manutenção da capacidade produtiva dos solos (Fageria \& Stone, 2004; Torres et al., 2005; Marchão et al., 2007). Um dos requisitos para garantir a eficiência desse sistema é a adequada cobertura do solo por espécies formadoras de palha (Hernani \& Salton, 2001; Andreotti et al., 2008), as quais devem ter elevada produção de biomassa e grande persistência sobre o solo (Kliemann et al., 2006), para que possam

Pesq. agropec. bras., Brasília, v.45, n.6, p.546-553, jun. 2010 
atuar efetivamente na proteção contra processos erosivos do solo, durante os períodos de excesso de água. Além disso, essas espécies devem favorecer maior retenção de umidade, em condições de deficit hídrico, e disponibilizar nutrientes às culturas por meio da ciclagem de nutrientes (Nunes et al., 2006). A camada de palha sobre a superfície do solo funciona como atenuadora ou dissipadora de energia, protege o solo contra o impacto direto das gotas de chuva, atua como obstáculo ao movimento do excesso de água que não infiltra no solo e impede o transporte de partículas minerais e orgânicas pela enxurrada (Heckler et al., 1998).

A produção de matéria seca acima de $6.000 \mathrm{~kg} \mathrm{ha}^{-1}$ é recomendada para uma adequada cobertura do solo em sistemas de plantio direto (Alvarenga et al., 2001; Nunes et al., 2006). Entretanto, essas informações são geradas para culturas de ciclo vegetativo menor que a do algodoeiro, que pode permanecer no campo por períodos superiores a 200 dias. Neste caso, a persistência da palha na superfície do solo deve ser alta, de forma que os benefícios da cobertura do solo sejam auferidos. A dificuldade de produção e manutenção de cobertura vegetal em regiões mais quentes, em razão do acelerado processo de decomposição, é bem documentada (Carter, 2001; Andreotti et al., 2008; Torres et al., 2008).

Portanto, para que o algodoeiro seja cultivado no sistema de semeadura direta sobre adequada quantidade de matéria seca, no bioma Cerrado, as espécies utilizadas para produção de palha devem ser semeadas imediatamente após a colheita da soja, no máximo até o final da primeira quinzena de março (Lamas, 2007). Machado \& Assis (2010) observaram que o uso de espécies perenes é importante para a obtenção de elevada produção de forragem, quando os cultivos de cobertura são plantados no final da época chuvosa.

O objetivo deste trabalho foi avaliar a produção, a persistência da biomassa seca e a eficiência da dessecação em espécies vegetais utilizadas para cultivos de cobertura do solo, e quantificar seus efeitos sobre a produtividade do algodoeiro em plantio direto, no Cerrado.

\section{Material e Métodos}

O trabalho foi conduzido em Santa Helena de Goiás, GO (17 $50^{\prime} 34^{\prime \prime} \mathrm{S} ; 50^{\circ} 35^{\prime} 58^{\prime \prime} \mathrm{W}$; altitude de $560 \mathrm{~m}$ ) em duas etapas: avaliação da produção e persistência da palha por espécies de cobertura do solo, e determinação da influência da biomassa de cobertura sobre a produtividade do algodoeiro, em sistema de semeadura direta. O solo da área experimental, classificado como Latossolo Vermelho, possuía a seguinte composição química antes da instalação do experimento: $\mathrm{pH}$ $\left(\mathrm{CaCl}_{2}\right), 5,9 ; \mathrm{Ca}^{2+}, 3,10 \mathrm{cmol}_{\mathrm{c}} \mathrm{dm}^{-3} ; \mathrm{Mg}^{2+}, 0,72 \mathrm{cmol}_{\mathrm{c}}$ $\mathrm{dm}^{-3} ; \mathrm{K}, 71 \mathrm{mg} \mathrm{dm}{ }^{-3} ; \mathrm{Al}^{3+}, 0,0 \mathrm{cmol}_{\mathrm{c}} \mathrm{dm}^{-3} ; \mathrm{H}+\mathrm{Al}$, 2,50 $\mathrm{cmol}_{\mathrm{c}} \mathrm{dm}^{-3} ; \mathrm{P}$ (Mehlich1), $6 \mathrm{mg} \mathrm{dm}{ }^{-3} ; \mathrm{S}, 9 \mathrm{mg}$ $\mathrm{dm}^{-3}$; MO, $28 \mathrm{~g} \mathrm{dm}^{-3}$; CTC, 6,5 $\mathrm{cmol}_{\mathrm{c}} \mathrm{dm}^{-3}$, e V, 62\%.

As precipitações e temperaturas máximas e mínimas, registradas na área experimental durante o período de condução dos trabalhos, são apresentadas na Figura 1.

O experimento consistiu de 16 tratamentos, de diferentes espécies, usadas para cobertura do solo: Panicum maximum, cultivares Mombaça, Tanzânia e Massai; Urochloa brizantha (Syn. Brachiaria brizantha), cultivares Piatã, Xaraés, Marandu e MG4; U. decumbens (Syn. B. decumbens); Paspalum atratum cv. Pojuca; Sorghum bicolor cultivares Santa Eliza e BRS 700; Pennisetum glaucum cv. ADR 500; Raphanus sativus; Eleusine coracana, Crotalaria spectabilis, além da testemunha em pousio. $\mathrm{O}$ delineamento experimental foi o de blocos ao acaso, com quatro repetições. As dimensões das parcelas experimentais eram de $10 \times 10 \mathrm{~m}$.

As espécies foram semeadas manualmente em 6 de março de 2007, em sulcos estreitos abertos mecanicamente, após colheita de soja precoce 'BRS Caiapônia'. O espaçamento entre as linhas foi de

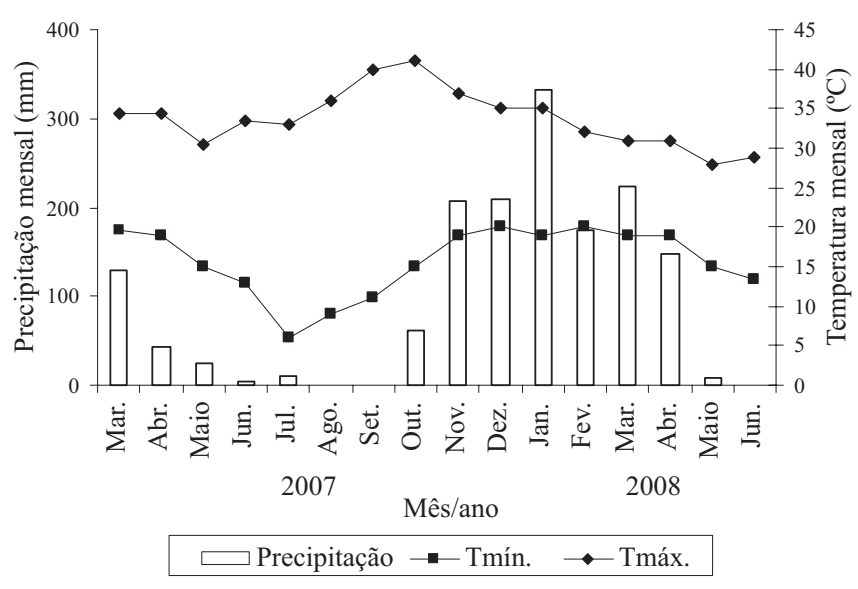

Figura 1. Precipitação mensal e médias mensais de temperaturas máximas e mínimas, ao longo do período de condução do experimento. 
0,45 m. Nenhuma espécie recebeu qualquer tipo de adubação ou irrigação.

No dia 22/11/2007 foi realizada a dessecação das plantas de cobertura com o herbicida glifosato na dose de $1.440 \mathrm{~g} \mathrm{ha}^{-1}$ do ingrediente ativo. Treze dias após a aplicação do herbicida, foi determinada, por dois avaliadores independentes, a eficiência de dessecação, conforme metodologia proposta por European Weed Research Council (1964). A espécie nabo-forrageiro não foi incluída nesta avaliação, pois o ciclo de vida dessa espécie encerrou durante o período do outono/ inverno, e as plantas já se encontravam mortas por ocasião da aplicação do herbicida. Um dia após a avaliação da eficiência da primeira dessecação, foi aplicado $1.680 \mathrm{~g} \mathrm{ha}^{-1}$ do i.a. glifosato e, em seguida, $60 \mathrm{~g} \mathrm{ha}^{-1}$ do i.a. flumioxazina, pois algumas espécies apresentam baixa facilidade de dessecação com apenas uma aplicação de glifosato.

As estimativas da produção e da persistência da biomassa seca pelas diferentes espécies vegetais foram realizadas por meio de amostragens em quatro épocas de avaliação: em 22/11/2007, imediatamente antes da primeira dessecação, e aos 70, 100 e 141 dias após essa data. Nas diferentes épocas, foram coletadas, ao acaso, três amostras da palha sobre a superfície do solo, em todas as parcelas experimentais, sendo cada amostra obtida de uma área de $0,25 \mathrm{~m}^{2}(0,5 \times 0,5 \mathrm{~m})$. Os resíduos de cobertura foram lavados em água corrente sobre peneira com malha de $1,6 \mathrm{~mm}$, de forma a retirar terra e impurezas. As amostras foram secas em estufa a $62^{\circ} \mathrm{C}$, até que atingissem massa constante. Com base nos resultados de persistência, ao longo do tempo da biomassa seca das espécies, foi calculada a área abaixo da curva de decomposição da biomassa seca (AACDB); para isso foram integrados todos os pontos das diferentes épocas de amostragem (Shaner \& Finney, 1977).

As taxas de decomposição da biomassa seca das espécies avaliadas foram estimadas por meio da função $\mathrm{y}=\mathrm{y}_{\mathrm{o}} \mathrm{e}^{-\mathrm{kt}}$, ajustada aos valores de massa de matéria seca da palha remanescente sobre o solo nas diferentes épocas de amostragem, em que y é a quantidade de matéria seca remanescente após um período de tempo t, em dias; $y_{o}$, a quantidade inicial de matéria seca; e k a constante de decomposição do resíduo. Por meio do valor de $\mathrm{k}$, foi calculado o tempo de meia-vida $\left(\mathrm{t}_{1 / 2}\right)$, que expressa o período de tempo necessário para que metade dos resíduos se decomponha (Espindola et al., 2006).

Sobre as parcelas do ensaio anterior, foi realizada a semeadura direta da cultivar de algodão BRS 269-Buriti, no dia 23/12/2007, com espaçamento de $0,90 \mathrm{~m}$ entre fileiras e com nove plantas por metro. A adubação de semeadura foi feita com $400 \mathrm{~kg} \mathrm{ha}^{-1}$ da formulação N-P-K 5-25-15 + 0,5\% de Zn e $0,2 \%$ de B. A primeira adubação em cobertura foi feita com $200 \mathrm{~kg} \mathrm{ha}^{-1}$ de sulfato de amônio, na fase B1, em que se verificou a emissão do primeiro botão floral, e a segunda adubação foi feita no início do florescimento (F1-F2), com $200 \mathrm{~kg} \mathrm{ha}^{-1}$ da formulação 20-0-30 + $0,4 \%$ de boro.

Para se testar a influência das diferentes espécies formadoras de palha na nutrição do algodoeiro, coletaram-se amostras da quinta folha, com inserção na haste principal, a partir do ápice, aos 85 dias após a emergência. As folhas foram secas em estufa, à temperatura de $62^{\circ} \mathrm{C}$, moídas e analisadas para determinação dos teores de macronutrientes $(\mathrm{N}, \mathrm{P}, \mathrm{K}$, $\mathrm{Ca}, \mathrm{Mg}$ e S), de acordo com Malavolta et al. (1997).

Na colheita do algodão, realizada em 3 de julho de 2008, foram tomadas cinco plantas ao acaso em três linhas centrais de cada parcela, para as determinações de altura média e número de capulhos por planta. Antes da colheita, foram retiradas amostras de 20 capulhos por parcela, da posição mediana de 20 plantas, para a determinação da massa média de um capulho e da percentagem de fibra. Para a avaliação da produtividade de algodão em caroço, foi realizada colheita em uma área de $27 \mathrm{~m}^{2}$, e os dados de produção em gramas por parcela foram transformados em quilograma por hectare. Após a separação das sementes da fibra, foram calculadas a percentagem e a produtividade de fibra.

Todas as análises foram realizadas com o auxílio do SAS (SAS Institute, 2002). Os dados foram submetidos à análise de variância e as médias foram comparadas por meio do teste de Tukey, a 5\% de probabilidade. Por não haver homogeneidade de variâncias, procedeu-se à análise não paramétrica, para a variável eficiência de dessecação, com o uso do procedimento FREQ (opção CMH2) para obter a estatística de Friedman. Apesar de o teste de Friedman calculado testar a hipótese de igualdade geral das médias, ele não fornece um mecanismo de comparação de médias subsequente a essa análise. Nesse caso, a comparação das médias foi realizada após o uso dos procedimentos RANK (rank transform) e GLM, conforme Ipe (1987). 


\section{Resultados e Discussão}

As espécies vegetais para formação de palha apresentaram diferenças significativas em relação à eficiência de dessecação (Friedman $\chi^{2}=48,11 ; \mathrm{P}=0,001$ ) (Tabela 1). Os tratamentos P. glaucum cv. ADR 500, E. coracana e S. bicolor cultivares BRS700 e Santa Eliza apresentaram, em ordem decrescente, as notas mais altas de eficiência de dessecação, e não diferiram significativamente entre si, mas sim em relação às espécies $P$. maximum cv. Tanzânia, $U$. decumbens, $U$. brizantha cv. Xaraés, C. spectabilis, P. maximum cv. Massai e $P$. atratum cv. Pojuca. Essas últimas quatro espécies apresentaram menor sensibilidade à dessecação e não diferiram significativamente entre si. Crotalaria spectabilis, P. maximum cv. Massai e P. atratum cv. Pojuca rebrotaram por ocasião do desenvolvimento do algodoeiro, mesmo com o manejo adicional com os herbicidas glifosato (1.680 $\left.\mathrm{g} \mathrm{ha}^{-1}\right) \mathrm{e}$ flumioxazina (60 $\mathrm{g} \mathrm{ha}^{-1}$ ), aplicados 17 dias antes da semeadura do algodoeiro. Diante disso, essas espécies tornaram-se invasoras, e tiveram de ser controladas por meio de herbicidas pós-emergentes graminicidas e de ação total em jato dirigido.

Tabela 1. Eficiência de dessecação das espécies de cobertura do solo, avaliadas 13 dias após aplicação do herbicida glifosato na dose de $1.440 \mathrm{~g}^{-1} \mathrm{e}^{-1}$ do i.a..

\begin{tabular}{lcc}
\hline Espécies & $\begin{array}{c}\text { Eficiência de } \\
\text { dessecação }^{(1)}\end{array}$ & $\begin{array}{c}\text { Valores transformados } \\
\text { em ranques }{ }^{(2)}\end{array}$ \\
\hline Pennisetum glaucum cv. ADR 500 & 100 & $13,50 \mathrm{a}$ \\
Eleusine coracana & 100 & $13,50 \mathrm{a}$ \\
Sorgum bicolor cv. BRS 700 & 91 & $11,86 \mathrm{ab}$ \\
Sorgum bicolor cv. Santa Eliza & 83 & $10,25 \mathrm{abc}$ \\
Urochloa brizantha cv. Piatã & 81 & $10,00 \mathrm{bc}$ \\
Urochloa brizantha cv. MG4 & 74 & $8,75 \mathrm{bc}$ \\
Panicum maximum cv. Mombaça & 73 & $7,75 \mathrm{~cd}$ \\
Urochloa brizantha cv. Marandu & 72 & $7,75 \mathrm{~cd}$ \\
Panicum maximum cv. Tanzânia & 60 & $5,38 \mathrm{de}$ \\
Urochloa decumbens & 51 & $5,13 \mathrm{de}$ \\
Urochloa brizantha cv. Xaraés & 46 & $3,88 \mathrm{ef}$ \\
Crotalaria spectabilis & 29 & $3,13 \mathrm{ef}$ \\
Panicum maximum cv. Massai & 28 & $2,63 \mathrm{ef}$ \\
Panicum atratum cv. Pojuca & 17 & $1,50 \mathrm{f}$ \\
\hline Estatística de Friedman $\left(\chi^{2}\right)$ & - & 48,11 \\
\hline
\end{tabular}

${ }^{(1)}$ Escala percentual de notas, na qual 0 corresponde à ausência de controle e 100 à dessecação total das plantas de cobertura. ${ }^{(2)}$ Médias seguidas por letras iguais, na coluna, não diferem significativamente entre si, pelo teste de Friedman, a 5\% de probabilidade.
Houve diferença significativa entre os tratamentos na primeira e quarta épocas de avaliação da matéria seca remanescente (Tabela 2). Na primeira época de avaliação, a maior produção de matéria seca foi a da espécie $P$. maximum cv. Tanzânia, que atingiu $16.647 \mathrm{~kg} \mathrm{ha}^{-1}$. Outras espécies, como $U$. decumbens, $S$. bicolor cv. BRS700, U. brizantha cultivares Marandu, MG4, Piatã, e Xaraés, $P$. maximum cv. Mombaça, S. bicolor cv. Santa Eliza, P. atratum $\mathrm{cv}$. Pojuca e $P$. maximum cv. Massai produziram acima de $9.000 \mathrm{~kg} \mathrm{ha}^{-1}$ de matéria seca, e não diferiram significativamente de $P$. maximum cv. Tanzânia. Conforme preconizam Alvarenga et al. (2001) e Nunes et al. (2006), a produção acima de $6.000 \mathrm{~kg} \mathrm{ha}^{-1}$ de matéria seca é desejável para a semeadura direta e para a cobertura do solo. Portanto, as quantidades de matéria seca produzidas por essas espécies são suficientes para implementação de sistema de semeadura direta. A produção de matéria seca do milheto (P. glaucum cv. ADR 500), que correspondeu a $8.604 \mathrm{~kg} \mathrm{ha}^{-1}$, embora tenha sido significativamente inferior à obtida por $P$. maximum cv. Tanzânia, também é considerada suficiente para a semeadura direta. Essas produtividades foram muito superiores às obtidas por Machado \& Assis (2010), que avaliaram a maioria das espécies utilizadas neste trabalho, no Mato Grosso do Sul, e não obtiveram produções de matéria seca maiores que $7.000 \mathrm{~kg} \mathrm{ha}^{-1}$. Essa discrepância entre os resultados possivelmente ocorreu em razão do plantio mais tardio e da menor fertilidade do solo no trabalho daqueles autores.

A espécie C. spectabilis produziu $5.840 \mathrm{~kg} \mathrm{ha}^{-1}$ de matéria seca, e não diferiu significativamente da espécie E. coracana e do pousio. Esses tratamentos produziram quantidades insuficientes de matéria seca para a semeadura direta do algodão.

Por ocasião da dessecação, o nabo-forrageiro (R. sativus) já havia encerrado o seu ciclo de vida, e os restos culturais estavam em estágio avançado de decomposição. Apesar da rápida liberação de nutrientes para a cultura subsequente, a acelerada degradação da biomassa seca do nabo-forrageiro é indesejável no que se refere à cobertura do solo (Crusciol et al., 2005).

$\mathrm{Na}$ quarta avaliação, aos 141 dias (Tabela 2), após a aplicação do herbicida dessecante, a matéria seca residual das espécies $U$. decumbens, $U$. brizantha cultivares Marandu, MG4, Piatã e Xaraés, S. bicolor 
cultivares BRS 700 e Santa Eliza, $P$. maximum cultivares Tanzânia, Mombaça e Massai e P. glaucum não diferiram significativamente entre si, sendo que a máxima quantidade de palha persistente no solo foi observada em $U$. decumbens (2.958 $\left.\mathrm{kg} \mathrm{ha}^{-1}\right)$, que diferiu significativamente das obtidas pelas espécies P. atratum cv. Pojuca, E. coracana, C. spectabilis, além do pousio.

Em relação à $C$. spectabilis, a baixa quantidade de matéria seca residual dessa leguminosa aos 141 dias da dessecação pode ser atribuída à pouca quantidade inicial produzida, já que suas taxas de decomposição foram menores do que as de $U$. decumbens (Tabela 3 ). Por ocasião do início das chuvas em outubro e novembro de 2007, a C. spectabilis emitiu novas brotações e folhas, que foram rapidamente decompostas após a dessecação. Contudo, a haste principal, responsável por boa parte da matéria seca residual dessa espécie, apresentou tempo de meia-vida igual a 64 dias, ou seja, não foi tão rapidamente decomposta. De acordo com Kliemann etal.(2006), leguminosas como o estilosantes (Stylosanthes guianensis cv. Mineirão) e o guandu-anão (Cajanus cajan) são facilmente decompostas. Pelá et al. (1999) avaliaram a resistência à decomposição de dez espécies de cobertura e observaram que o milheto foi a mais resistente, com $44,4 \%$ de perda de matéria seca em 73 dias, enquanto o guandu-anão, a C. spectabilis e a mucuna-preta (Stizolobium aterrimum) perderam $49,4,60,21$ e 57,42\%, respectivamente. No entanto, Torres et al. (2008) observaram maior persistência da palha de leguminosas (C. spectabilis e $C$. cajan) em relação a gramíneas (B. brizantha, $S$. bicolor e Avena sativa).

Na comparação de todas as épocas de avaliação, observa-se que a maior área abaixo da curva de decomposição da matéria seca (AACDB) foi da espécie P. maximum cv. Tanzânia, seguida da $U$. decumbens, $S$. bicolor cv. BRS 700, U. brizantha cultivares Piatã, Marandu, MG4, e Xaraés, $P$. maximum cultivares Mombaça e Massai e P. atratum cv. Pojuca; contudo, sem diferenças estatisticamente significativas entre elas (Tabela 2). O valor adimensional da AACDB conjuga produção e persistência da palha sobre o solo, e permite uma avaliação mais acurada da capacidade da espécie em proporcionar uma cobertura persistente do solo. Assim, observa-se que a AACDB de $P$. maximum cv. Tanzânia foi significativamente superior às obtidas pelas espécies $S$. bicolor cv. Santa Eliza, P. glaucum, C. spectabilis, E. coracana e pelas plantas daninhas que se desenvolveram no pousio.

Tabela 2. Massa de matéria seca $\left(\mathrm{kg} \mathrm{ha}^{-1}\right)$ das espécies utilizadas para cobertura do solo, nas diferentes épocas de avaliação $^{(1)}$.

\begin{tabular}{|c|c|c|c|c|c|}
\hline \multirow[t]{2}{*}{ Espécie } & \multicolumn{4}{|c|}{ Dias após dessecação } & \multirow[t]{2}{*}{$\mathrm{AACDB}^{(2)}$} \\
\hline & 0 & 70 & 100 & 141 & \\
\hline Panicum maximum cv. Tanzânia & $16.647 \mathrm{a}$ & $3.884 \mathrm{a}$ & $2.793 a$ & 1.792abcde & $1.002 .391 \mathrm{a}$ \\
\hline Urochloa decumbens & $14.777 \mathrm{ab}$ & $4.752 \mathrm{a}$ & $3.247 \mathrm{a}$ & $2.958 \mathrm{a}$ & $931.468 \mathrm{ab}$ \\
\hline Sorghum bicolor cv. BRS 700 & $13.837 \mathrm{ab}$ & $4.546 \mathrm{a}$ & $2.896 \mathrm{a}$ & $2.423 \mathrm{abc}$ & $864.083 \mathrm{ab}$ \\
\hline Urochloa brizantha cv. Marandu & $12.451 \mathrm{abc}$ & $4.708 \mathrm{a}$ & $3.070 \mathrm{a}$ & $2.223 \mathrm{abcd}$ & $825.733 \mathrm{ab}$ \\
\hline Urochloa brizantha cv. MG4 & $12.228 \mathrm{abc}$ & $4.031 \mathrm{a}$ & $2.907 \mathrm{a}$ & $2.707 \mathrm{ab}$ & $788.222 \mathrm{abc}$ \\
\hline Urochloa brizantha cv. Piatã & $10.671 \mathrm{abcd}$ & $4.262 \mathrm{a}$ & $3.158 \mathrm{a}$ & $2.577 \mathrm{ab}$ & $846.219 \mathrm{ab}$ \\
\hline Urochloa brizantha cv. Xaraés & $10.465 \mathrm{abcd}$ & $3.622 \mathrm{a}$ & $3.184 \mathrm{a}$ & $2.591 \mathrm{ab}$ & 713.514abcd \\
\hline Panicum maximum cv. Mombaça & $10.361 \mathrm{abcde}$ & $3.758 \mathrm{a}$ & $1.944 \mathrm{a}$ & $1.855 \mathrm{abcde}$ & $657.557 \mathrm{abcd}$ \\
\hline Sorghum bicolor cv. Santa Eliza & 9.769abcde & $2.901 \mathrm{a}$ & $2.246 \mathrm{a}$ & 2.027abcde & $608.234 \mathrm{bcde}$ \\
\hline Paspalum atratum cv. Pojuca & $9.356 \mathrm{abcde}$ & $4.047 \mathrm{a}$ & $2.092 \mathrm{a}$ & $1.374 \mathrm{bcde}$ & $632.252 \mathrm{abcde}$ \\
\hline Panicum maximum cv. Massai & 9.279abcde & $3.349 \mathrm{a}$ & $2.057 \mathrm{a}$ & 1.939abcde & 639.200abcde \\
\hline Pennisetum glaucum cv. ADR 500 & $8.604 \mathrm{bcde}$ & $3.001 \mathrm{a}$ & $1.929 \mathrm{a}$ & 1.599abcde & $552.449 \mathrm{bcde}$ \\
\hline Crotalaria spectabilis & $5.840 \mathrm{cde}$ & $2.840 \mathrm{a}$ & $2.419 \mathrm{a}$ & $777 \mathrm{e}$ & $423.815 \mathrm{cde}$ \\
\hline Eleusine coracana & $3.602 \mathrm{de}$ & $3.065 \mathrm{a}$ & $1.537 \mathrm{a}$ & $1.075 \mathrm{cde}$ & $355.921 \mathrm{de}$ \\
\hline Pousio $^{(3)}$ & $2.648 \mathrm{e}$ & $1.975 \mathrm{a}$ & $903 a$ & 911de & $249.979 \mathrm{e}$ \\
\hline Média & 10.036 & 3.674 & 2.445 & 1.933 & 671.685 \\
\hline Coeficiente de variação (\%) & 30,50 & 30,51 & 39,99 & 26,69 & 21,22 \\
\hline
\end{tabular}

Pesq. agropec. bras., Brasília, v.45, n.6, p.546-553, jun. 2010 
Quanto mais altos forem os conteúdos de lignina e a relação $\mathrm{C} / \mathrm{N}$ nos resíduos vegetais, mais lenta será a sua taxa de decomposição (Floss, 2000; Sainju et al., 2007), e maior será a proteção do solo. A maior persistência de matéria seca no solo é importante para a cultura do algodoeiro, que apresenta ciclo longo, proporciona pequena proteção do solo durante um período relativamente grande, enecessita de umidade no solo para formação das últimas maçãs, que geralmente perdura até seis meses após a semeadura.

Embora a espécie E. coracana tenha apresentado a menor taxa de decomposição e o maior tempo de meia-vida (Tabela 3), nas condições em que o trabalho foi conduzido, a produção de matéria seca dessa espécie foi significativamente menor que de várias outras espécies avaliadas. Entretanto, Boer et al. (2008) relataram produção de matéria seca por $E$. coracana de $8.753 \mathrm{~kg} \mathrm{ha}^{-1}$, possivelmente em razão do uso de fertilização química, que não foi utilizada neste trabalho.

Não houve diferença significativa para as variáveis: altura das plantas de algodoeiro, com média de $128 \mathrm{~cm}$; número de capulhos por planta, média de 16,6; população, média de 70.528 plantas ha ${ }^{-1}$; massa de um capulho, média de $6,5 \mathrm{~g}$, e percentagem de fibra, média de 41,9\%. Lamas (2007) também não observou diferença significativa para altura de planta e percentagem de fibra de algodoeiros cultivados sobre palha de diferentes espécies vegetais.
As espécies avaliadas, no entanto, influenciaram significativamente as produtividades de algodão em caroço e de fibra (Tabela 4). Tal resultado pode ter sido decorrente da maior persistência da palha de algumas espécies no solo, que teriam proporcionado maior disponibilidade hídrica aos algodoeiros. A palha de cobertura atua como reguladora de temperatura e da água do solo, no enriquecimento de matéria orgânica e no favorecimento do desenvolvimento de raízes, além de atuar como barreira física a algumas plantas daninhas e na prevenção da erosão (Kluthcouski et al., 2003).

As maiores produtividades foram obtidas quando o algodoeiro foi cultivado sobre a espécie $P$. maximum cv. Tanzânia, seguido da espécie $P$. maximum cv. Mombaça, que não diferiram significativamente entre si (Tabela 4). As produtividades de fibra do algodoeiro cultivado sobre os restos vegetais de P. maximum cultivares Tanzânia e Mombaça diferiram significativamente em relação ao cultivo após o pousio, nabo-forrageiro e $P$. atratum cv. Pojuca.

As produtividades de algodão em caroço e de fibra obtidas quando o algodoeiro foi cultivado sobre os resíduos de $C$. spectabilis não diferiu das produtividades mais altas (Tabela 4). Essa espécie leguminosa, provavelmente em razão da fixação biológica de nitrogênio, possibilitou boa produtividade do algodoeiro, apesar de os seus benefícios na proteção do solo serem pouco relevantes, em virtude

Tabela 3. Taxa de decomposição $(\mathrm{k})$ e meia-vida $\left(\mathrm{t}_{1 / 2}\right)$ da palha das espécies avaliadas para cobertura do solo, estimadas pela função $\mathrm{y}=\mathrm{y}_{0} \mathrm{e}^{-\mathrm{kt}}$.

\begin{tabular}{|c|c|c|c|c|c|}
\hline Espécies & $\begin{array}{c}\text { Regressão para } \\
\text { decomposição }\end{array}$ & $\mathrm{R}^{2}$ & $\begin{array}{c}\text { Massa de matéria seca no } \\
\text { tempo zero }\left(\mathrm{kg} \mathrm{ha}^{-1}\right)\end{array}$ & $\mathrm{k}$ & $t_{1 / 2}($ dias $)$ \\
\hline Panicum maximum cv. Tanzânia & $\mathrm{y}=16.584 \mathrm{e}^{-0,0188 \mathrm{t}}$ & $0,99 * *$ & 16.584 & 0,0188 & 37 \\
\hline Urochloa decumbens & $\mathrm{y}=14.659 \mathrm{e}^{-0,0145 \mathrm{t}}$ & $0,99 * *$ & 14.659 & 0,0145 & 48 \\
\hline Sorghum bicolor cv. BRS 700 & $\mathrm{y}=13.767 \mathrm{e}^{-0,0149 \mathrm{t}}$ & $0,99 * *$ & 13.767 & 0,0149 & 47 \\
\hline Urochloa brizantha cv. Marandu & $\mathrm{y}=12.414 \mathrm{e}^{-0,0135 t}$ & $0,97 * *$ & 12.414 & 0,0135 & 51 \\
\hline Urochloa brizantha cv. MG4 & $\mathrm{y}=12.103 \mathrm{e}^{-0,0138 \mathrm{t}}$ & $0,99^{*}$ & 12.103 & 0,0138 & 50 \\
\hline Urochloa brizantha cv. Piatã & $\mathrm{y}=10.577 \mathrm{e}^{-0,0118 \mathrm{t}}$ & $0,99 * *$ & 10.577 & 0,0118 & 59 \\
\hline Urochloa brizantha cv. Xaraés & $\mathrm{y}=10.312 \mathrm{e}^{-0,0122 \mathrm{t}}$ & $0,99 * *$ & 10.312 & 0,0122 & 57 \\
\hline Panicum maximum cv. Mombaça & $\mathrm{y}=10.337 \mathrm{e}^{-0,0146 \mathrm{t}}$ & $0,87 *$ & 10.337 & 0,0146 & 47 \\
\hline Sorghum bicolor cv. Santa Eliza & $\mathrm{y}=9.664 \mathrm{e}^{-0,0146 t}$ & $0,98 *$ & 9.664 & 0,0146 & 47 \\
\hline Paspalum atratum cv. Pojuca & $\mathrm{y}=9.402 \mathrm{e}^{-0,0134 t}$ & $0,99 * *$ & 9.402 & 0,0134 & 52 \\
\hline Panicum maximum cv. Massai & $\mathrm{y}=9.222 \mathrm{e}^{-0,0137 t}$ & $0,98 * *$ & 9.222 & 0,0137 & 51 \\
\hline Pennisetum glaucum cv. ADR 500 & $\mathrm{y}=8.560 \mathrm{e}^{-0,0141 \mathrm{t}}$ & $0,98 * *$ & 8.560 & 0,0141 & 49 \\
\hline Crotalaria spectabilis & $\mathrm{y}=5.895 \mathrm{e}^{-0,0108 \mathrm{t}}$ & $0,97 * *$ & 5.895 & 0,0108 & 64 \\
\hline Eleusine coracana & $\mathrm{y}=3.789 \mathrm{e}^{-0,0071 \mathrm{t}}$ & $0,81 *$ & 3.789 & 0,0071 & 98 \\
\hline
\end{tabular}

* e **Significativo a $5 \%$ e $1 \%$ de probabilidade, respectivamente, pelo teste $\mathrm{F}$. 
Tabela 4. Produtividade do algodoeiro, quando cultivado sobre o resíduo das diferentes espécies utilizadas para a cobertura do solo ${ }^{(1)}$

\begin{tabular}{lcc}
\hline Espécies & Algodão em caroço $\left(\mathrm{kg} \mathrm{ha}^{-1}\right)$ & Algodão em fibra $\left(\mathrm{kg}\right.$ ha $\left.{ }^{-1}\right)$ \\
\hline Panicum maximum cv. Tanzânia & $5.840 \mathrm{a}$ & $2.436 \mathrm{a}$ \\
Urochloa decumbens & $5.143 \mathrm{abcde}$ & $2.156 \mathrm{abcd}$ \\
Sorghum bicolor cv. BRS 700 & $5.112 \mathrm{abcde}$ & $2.124 \mathrm{abcd}$ \\
Urochloa brizantha cv. Marandu & $5.028 \mathrm{bcde}$ & $2.119 \mathrm{abcd}$ \\
Urochloa brizantha cv. MG4 & $5.493 \mathrm{abcd}$ & $2.310 \mathrm{ab}$ \\
Urochloa brizantha cv. Piatã & $5.483 \mathrm{abcd}$ & $2.298 \mathrm{abc}$ \\
Urochloa brizantha cv. Xaraés & $5.233 \mathrm{abcde}$ & $2.211 \mathrm{abcd}$ \\
Panicum maximum cv. Mombaça & $5.775 \mathrm{ab}$ & $2.417 \mathrm{a}$ \\
Sorghum bicolor cv. Santa Eliza & $5.324 \mathrm{abcde}$ & $2.236 \mathrm{abcd}$ \\
Paspalum atratum cv. Pojuca & $4.906 \mathrm{cde}$ & $2.058 \mathrm{bcd}$ \\
Panicum maximum cv. Massai & $4.997 \mathrm{bcde}$ & $2.121 \mathrm{abcd}$ \\
Pennisetum glaucum cv. ADR 500 & $5.397 \mathrm{abcde}$ & $2.256 \mathrm{abcd}$ \\
Crotalaria spectabilis & $5.534 \mathrm{abc}$ & $2.290 \mathrm{abc}$ \\
Eleusine coracana & $5.317 \mathrm{abcde}$ & $2.225 \mathrm{abcd}$ \\
Raphanus sativus & $4.701 \mathrm{de}$ & $1.947 \mathrm{~d}$ \\
Pousio & $4.646 \mathrm{e}$ & $1.969 \mathrm{~cd}$ \\
\hline Média & 5.236 & 2.195 \\
\hline Coeficiente de variação (\%) & 5,92 & 5,94 \\
\hline
\end{tabular}

${ }^{(1)}$ Médias seguidas por letras iguais, na coluna, não diferem significativamente entre si, pelo teste de Tukey, a 5\% de probabilidade.

da baixa produção de matéria seca. Na comparação das produtividades de algodão em caroço após C. spectabilis, nabo-forrageiro e pousio, houve diferença significativa entre esses tratamentos, com maior produtividade após $C$. spectabilis.

As diferentes espécies vegetais para formação de palha não influenciaram os teores foliares dos nutrientes $\mathrm{N}, \mathrm{P}, \mathrm{K}, \mathrm{Ca}, \mathrm{Mg}$ e $\mathrm{S}$ no algodoeiro. Os teores de $\mathrm{N}(38,5$ a 44,4 $\left.\mathrm{g} \mathrm{kg}^{-1}\right)$ e Ca $\left(27,1\right.$ a 32,3 $\left.\mathrm{g} \mathrm{kg}^{-1}\right)$ foram semelhantes aos obtidos em lavouras de alta produtividade, no cerrado brasileiro (Yamada et al., 1999). Os teores de $\mathrm{P}\left(1,9\right.$ a 2,5 $\left.\mathrm{g} \mathrm{kg}^{-1}\right)$, K (12,4 a 16,1 $\left.\mathrm{g} \mathrm{kg}^{-1}\right)$, $\operatorname{Mg}\left(2,4\right.$ a $\left.3 \mathrm{~g} \mathrm{~kg}^{-1}\right)$ e $\mathrm{S}\left(1,5\right.$ a $\left.2 \mathrm{~g} \mathrm{~kg}^{-1}\right)$, no entanto, ficaram abaixo das concentrações consideradas adequadas para áreas de alta produtividade de algodão (Yamada et al., 1999).

Com base nos resultados das características de produção de matéria seca, facilidade de dessecação, persistência de palha e produtividade do algodoeiro, as espécies $P$. maximum, cultivares Tanzânia e Mombaça, U. brizantha, cultivares MG4, Piatã e Xaraés, S. bicolor, cv. Santa Eliza e P. glaucum podem ser consideradas as mais adequadas para o cultivo do algodoeiro no sistema de semeadura direta.

\section{Conclusões}

1. As espécies $P$. maximum (cv. Tanzânia, Mombaça e Massai), U. decumbens, S. bicolor (cv. BRS 700 e Santa Eliza), U. brizantha (cv. Marandu, MG4, Piatã, e Xaraés) e $P$. atratum (cv. Pojuca), produzem matéria seca em quantidade suficiente para que sejam aproveitadas no sistema de plantio direto do algodoeiro.

2. As espécies $C$. spectabilis, $P$. maximum (cv. Massai), P. atratum (cv. Pojuca) e U. brizantha (cv. Xaraés) apresentam menor sensibilidade ao herbicida dessecante glifosato.

3. As produtividades do algodoeiro cultivado sobre palhas das gramíneas $P$. maximum (cv. Tanzânia e Mombaça) são superiores às obtidas após o pousio, e sobre palha de R. sativus e P. atratum (cv. Pojuca).

\section{Referências}

ALVARENGA, R.C.; LARA CABEZAS, W.A.; CRUZ, J.C.; SANTANA, D.P. Plantas de cobertura de solo para sistema plantio direto. Informe Agropecuário, v.22, p.25-36, 2001.

ANDREOTTI, M.; ARALDI, M.; GUIMARÃES, V.F.; FURLANI JUNIOR, E.; BUZETTI, S. Produtividade do milho safrinha e modificações químicas de um Latossolo em sistema plantio direto em função de espécies de cobertura após calagem superficial. Acta Scientiarum Agronomy, v.30, p.109-115, 2008. 
BOER, C.A.; ASSIS, R.L. de; SILVA, G.P.; BRAZ, A.J.B.P.; BARROSO, A.L. de L.; CARGNELUTTI FILHO, A.; PIRES, F.R. Biomassa seca, decomposição e cobertura do solo ocasionada por resíduos culturais de três espécies vegetais na região Centro-Oeste do Brasil. Revista Brasileira de Ciência do Solo, v.32, p.843-851, 2008.

CARTER, M.R. Organic matter and sustainability. In: REES, R.M.; BALL, B.C.; CAMPBELL, C.D.; WATSON, C.A. Sustainable management of soil organic matter. Wallingford: CABI Publishing, 2001. p.9-22.

COMPANHIA NACIONAL DE ABASTECIMENTO. Central de informações agropecuárias. Algodão Brasil: série histórica de área plantada. 2009. Disponível em: <http://www.conab.gov.br/ conabweb/download/safra/AlgodaoSerieHist.xls>. Acesso em: 20 jul. 2009.

CRUSCIOL, C.A.C.; COTTICA, R.L.; LIMA, E. do V.; ANDREOTTI, M.; MORO, E.; MARCON, E. Persistência de palhada e liberação de nutrientes do nabo forrageiro no plantio direto. Pesquisa Agropecuária Brasileira, v.40, p.161-168, 2005.

ESPINDOLA, J.A.A.; GUERRA, J.G.M.; ALMEIDA, D.L. de; TEIXEIRA, M.G.; URQUIAGA, S. Decomposição e liberação de nutrientes acumulados em leguminosas herbáceas perenes consorciadas com bananeiras. Revista Brasileira de Ciência do Solo, v.30, p.321-328, 2006.

EUROPEAN WEED RESEARCH COUNCIL. Report of the $3^{\text {rd }}$ and $4^{\text {rd }}$ meetings of EWRC Committee of methods in weed research. Weed Research, v.4, p.88, 1964.

FAGERIA, N.K.; STONE, C.F. Produtividade de feijão no sistema plantio direto com aplicação de calcário e zinco. Pesquisa Agropecuária Brasileira, v.39, p.73-78, 2004.

FLOSS, E. Benefícios da biomassa seca de aveia ao sistema de semeadura direta. Revista Plantio Direto, v.57, p.25-29, 2000.

HECKLER, J.C.; HERNANI, L.C.; PITOL, C. Palha. In: SALTON, J.C.; HERNANI, L.C.; FONTES, C.Z. (Org.). Sistema plantio direto: o produtor pergunta, a Embrapa responde. Dourados: Embrapa-CPAO, 1998. p.37-49. (Coleção 500 perguntas 500 respostas).

HERNANI, L.C.; SALTON, J.C. Manejo e conservação do solo. In: ALGODÃO: tecnologia de produção. Dourados: Embrapa Agropecuária Oeste; Campina Grande: Embrapa Algodão, 2001. p.76-102.

IPE, D. Performing the Friedman test and associated multiple comparison test using PROC GLM. Proceedings of the Twelfth Annual SAS Users Group International Conference, v.12, p.1146-1148, 1987.

KLIEMANN, H.J.; BRAZ, A.J.P.B.; SILVEIRA, P.M. da. Taxas de decomposição de resíduos de espécies de cobertura em Latossolo Vermelho distroférrico. Pesquisa Agropecuária Tropical, v.36, p.21-28, 2006.
KLUTHCOUSKI, J.; STONE, L.F.; AIDAR, H. (Ed.). Integração lavoura-pecuária. Santo Antonio de Goiás: Embrapa Arroz e Feijão, 2003. 570p.

LAMAS, F.M. Espécies para cobertura do solo e seus efeitos no algodoeiro. Revista Brasileira de Oleaginosas e Fibrosas, v.11, p.55-63, 2007.

MACHADO, L.A.Z; ASSIS, P.G.G. de. Produção de palha e forragem por espécies anuais e perenes em sucessão à soja. Pesquisa Agropecuária Brasileira, v.45, p.415-422, 2010.

MALAVOLTA, E.; VITTI, G.C.; OLIVEIRA, S.A. de. Avaliação do estado nutricional das plantas: princípios e aplicações. 2.ed. Piracicaba: Potafos, 1997. 319p.

MARCHÃO, R.L.; BALBINO, L.C.; SILVA, E.M. da; SANTOS JÚNIOR, J. de D.G. dos; SÁ, M.A.C.; VILELA, L.; BECQUER, T. Qualidade física de um Latossolo Vermelho sob sistemas de integração lavoura-pecuária no Cerrado. Pesquisa Agropecuária Brasileira, v.42, p.873-882, 2007.

NUNES, U.R.; ANDRADE JÚNIOR, V.C.; SILVA, E. de B.; SANTOS, N.F.; COSTA, H.A.O.; FERREIRA, C.A. Produção de palhada de plantas de cobertura e rendimento do feijão em plantio direto. Pesquisa Agropecuária Brasileira, v.41, p.943-978, 2006.

PELÁ, A.; SILVA, M.S.; COSTA, L.A. da; SILVA, C.J. da; ZUCARELI, C.; DECARLI, L. D.; MATTER, U.F. Avaliação da resistência à decomposição de dez espécies de plantas de cobertura visando o plantio direto. Revista Plantio Direto, v.53, p.26-33, 1999.

SAINJU, U.M.; SCHOMBERG, H.H.; SINGH, B.P.; WHITEHEAD, W.F.; TILLMAN, P.G.; LACHNICHT-WEYERS, S.L. Cover crop effect on soil carbon fractions under conservation tillage cotton. Soil \& Tillage Research, v.96, p.205-218, 2007.

SAS INSTITUTE. SAS user's guide. Version 9.1. Cary: SAS Institute, 2002.

SHANER, G.; FINNEY, R.E. The effect of nitrogen fertilization on the expression of slow-mildewing resistance in Knox wheat. Phytopathology, v.67, p.1051-1056, 1977.

TORRES, J.L.R.; PEREIRA, M.G.; ANDRIOLI, I.; POLIDORO, J.C.; FABIAN, A.J. Decomposição e liberação de nitrogênio de resíduos culturais de plantas de cobertura em um solo de cerrado. Revista Brasileira de Ciência do Solo, v.29, p.609-618, 2005.

TORRES, J.L.R.; PEREIRA, M.G.; FABIAN, A.J. Produção de fitomassa por plantas de cobertura e mineralização de seus resíduos em plantio direto. Pesquisa Agropecuária Brasileira, v.43, p.421-428, 2008.

YAMADA, T.; MALAVOLTA, E.; MARTINS, O.C.; ZANCANARO, L.; CASALE, H.; BAPTISTA, I. Teores foliares de nutrientes observados em áreas de alta produtividade. Piracicaba: Potafos, 1999.

$\overline{\text { Recebido em } 11 \text { de março de } 2010 \text { e aprovado em } 30 \text { de maio de } 2010}$ 